\title{
A design method of thermoelectric cooler
}

\author{
B.J. Huang*, C.J. Chin, C.L. Duang \\ Department of Mechanical Engineering, National Taiwan University, Taipei, Taiwan
}

Received 4 May 1998; received in revised form 5 April 1999; accepted 18 August 1999

\begin{abstract}
A system design method of thermoelectric cooler is developed in the present study. The design calculation utilizes the performance curve of the thermoelectric module that is determined experimentally. An automatic test apparatus was designed and built to illustrate the testing. The performance test results of the module are used to determine the physical properties and derive an empirical relation for the performance of thermoelectric module. These results are then used in the system analysis of a thermoelectric cooler using a thermal network model. The thermal resistance of heat sink is chosen as one of the key parameters in the design of a thermoelectric cooler. The system simulation shows that there exists a cheapest heat sink for the design of a thermoelectric cooler. It is also shown that the system simulation coincides with experimental data of a thermoelectric cooler using an air-cooled heat sink with thermal resistance $0.2515^{\circ} \mathrm{C} / \mathrm{W}$. An optimal design of thermoelectric cooler at the conditions of optimal COP is also studied. The optimal design can be made either on the basis of the maximum value of the optimal cooling capacity, or on the basis of the best heat sink technology available. (C) 2000 Elsevier Science Ltd and IIR. All rights reserved.
\end{abstract}

Keywords: Thermoelectric cooling; Thermoelectric cooler design

\section{Conception d'un refroidisseur thermoélectrique}

\section{Résumé}

Dans cette étude, on a développé une méthode pour concevoir un refroidisseur thermoélectrique. La calcul donnant lieu à la conception est fondé sur la courbe de performance (déterminée de facon expérimentale) du module thermoélectrique. Un appareil a été conç et construit afin d'effectuer et visualiser les essais effectués. Les résultats obtenus en termes de performance du module ont été utilisés afin de déterminer les propriétés physiques et d'établir une relation empirique pour la performance. Les résultats obtenus ainsi sont alors utilisés dans l'analyse d'un refroidisseur thermoélectrique fondé sur un modèle de réseau thermique. La résistance thermique du puits thermique est sélectionnée comme l'un des paramètres clés dans la conception d'un refroidisseur thermoélectrique. La simulation de ce système montre qu'il existe un puits thermique bon marché à utiliser dans la conception d'un refroidisseur thermoélectrique. Les auteurs montrent également que la simulation du système concorde avec les données expérimentales sur un refroidisseur thermoélectrique utilisant un puits thermique refroidi par l'air avec une résistance thermique de 0,2515 $\mathrm{C} / \mathrm{W}$. La conception optimale d'un refroidisseur thermoélectrique dans les conditions de COP optimal est aussi analysée ici. Une conception optimale peut être fondée sur la valeur maximale de puissance frigorifique ou sur la meilleure technologie de puits thermique disponible. (C) 2000 Elsevier Science Ltd and IIR. All rights reserved.

Mots clés: Système frigorifique; Thermoélectricité; Equipement; Conception; COP; Optimisation; Procédé

\footnotetext{
* Corresponding author. Tel.: + 886-2-2363-4790; fax: + 886-2-2364-0549.

E-mail address: bjhuang@tpts6.seed.net.tw (B.J. Huang)
} 


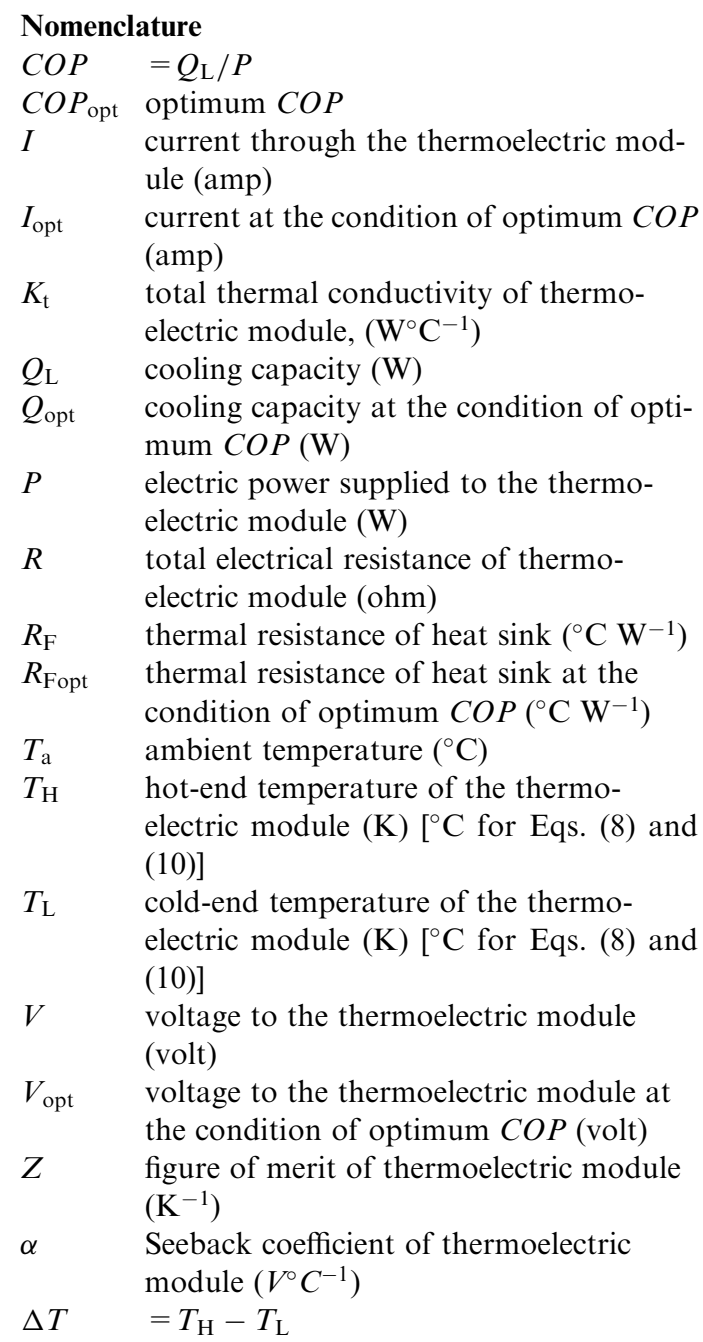

\section{Introduction}

Thermoelectric cooler has been widely used in military, aerospace, instrument, and industrial or commercial products, as a cooling device for specific purposes [1-3]. This technology has existed for about 40 years. Many researchers are concerned about the physical properties of the thermoelectric material and the manufacturing technique of thermoelectric modules. In addition to the improvement of the thermoelectric material and module, the system analysis of a thermoelectric cooler is equally important in designing a high-performance thermoelectric cooler. This is however sometimes ignored by many researchers.

The design procedure of a thermoelectric cooler usually follows the performance curves of the thermoelectric module which is provided by the manufacturer. Usually, the design of a thermoelectric cooler starts from a given temperature difference across the hot and cold sides of the module $\Delta T\left(=T_{\mathrm{H}}-T_{\mathrm{L}}\right)$ and the required cooling capacity $Q_{\mathrm{L}}$ [4]. The current $I$ for the thermoelectric module is determined from a measured $\Delta T-I$ curve at a fixed $Q_{\mathrm{L}}$. The $V-I$ curves at zero cooling capacity $\left(Q_{\mathrm{L}}=0\right)$ and at zero temperature difference $(\Delta T=0)$ are then used to determine the voltages $V$ as the upper and the lower bonds, respectively. The required thermal resistance of the heat sink is finally evaluated. An iteration procedure is necessary since the heat sink design may not be feasible and the assumed $\Delta T$ may not be practical. In addition, the above design method only determines the range of the applied voltage. The actual value of $V$ needs to be determined experimentally.

In the present study, we develop another design method for the thermoelectric cooler. The performance curves and the basic physical properties of a thermoelectric module are first measured from a module test. Using a thermal network model and the measured results of the module, we carry out a system analysis of a thermoelectric cooler. The results are then used for the system design. The present study uses the thermal resistance of the heat sink as one of the key parameters in the design of a thermoelectric cooler.

\section{Performance test of a thermoelectric module}

The thermal performance of a thermoelectric module depends on the physical properties such as the Seebeck coefficient $\alpha$, the electric resistance $R$, and the thermal conductivity $K_{\mathrm{t}}$. In general, these properties may vary with operating temperature. The manufacturer of thermoelectric module usually does not provide this kind of data for their customer or the given data are not accurate due to the variation of manufacturing process. We develop a testing apparatus with a standard operating procedure and a software package which can be used to measure and analyze the physical properties and the thermal performance curves of a thermoelectric module.

\subsection{Experimental apparatus for thermoelectric module test}

In the performance test of a thermoelectric module, we need to measure the cold-end temperature $T_{\mathrm{L}}$, the current $I$, and the voltage $V$ at steady state under various hot-end temperature $T_{\mathrm{H}}$ and cooling capacity $Q_{\mathrm{L}}$. The measurement is quite lengthy and thus it requires automation in order to reduce errors resulting from manual operation.

Shown in Fig. 1 is the experimental apparatus for the thermoelectric module test. The thermoelectric module is clamped between a cooling jacket and a heater block. The heater block is made from aluminum. Four cartridge-type electric heaters with total resistance $61.1 \Omega$ are inserted inside the block to provide an emulated cooling capacity $Q_{\mathrm{L}}$ which is proportional to the applied voltage. The 


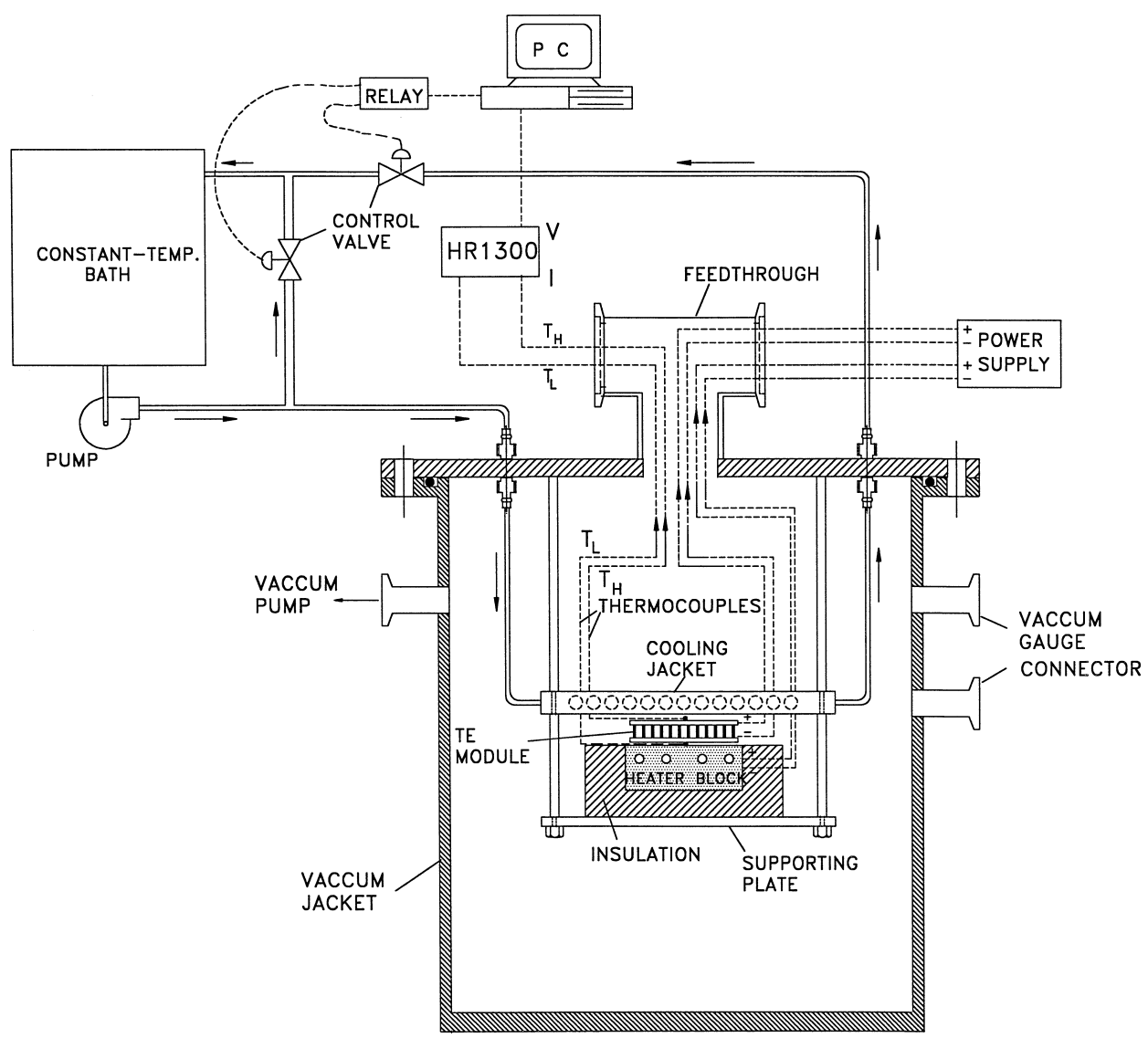

Fig. 1. Thermoelectric module test apparatus.

Fig. 1. Appareil utilisé pour tester le module thermoélectrique.

heating rate $Q_{\mathrm{L}}$ can be automatically controlled by a PC through a D/A interface card and a DC power amplifier.

The cooling jacket is a plate-type heat exchanger with coolant (glycol solution) flowing through the interior channels for controlling the hot end temperature of the thermoelectric module $T_{\mathrm{H}}$. The coolant is supplied from a constant-temperature bath at a fixed temperature. Immersed in the bath are a cooling coil that is operated by a small refrigerator and an electrical heating coil that is powered by electricity. Therefore, the coolant temperature in the bath can be adjusted to a temperature above or below the room temperature. The temperature of the coolant in the bath is controlled by a PID controller to within $\pm 0.5^{\circ} \mathrm{C}$ uncertainty. For automation, the temperature setting of the PID controller is triggered remotely by the PC through a communication interface RS485.

To control the hot-end temperature $T_{\mathrm{H}}$, the coolant flow through the cooling jacket is turned on and off by two control valves installed in the flow lines. By regulating the duration of On and Off according to a control scheme, $T_{\mathrm{H}}$ can be regulated to within $\pm 1^{\circ} \mathrm{C}$. To reduce the heat leakage to the thermoelectric module during the test, the test section is put in a vacuum jacket which is evacuated to $10^{-3}$ torr by a vacuum pump.

All the temperatures are measured by T-type thermocouples and recorded by a Yokogawa hybrid recorder HR1300 with an uncertainty $\pm 0.5^{\circ} \mathrm{C}$. The voltages and currents supplied to the test section are also measured by HR1300. All the measured signals are then sent to the PC through IEEE488 interface. Each test run will take about $30 \mathrm{~min}$ to reach a steady state.

\subsection{Operating procedures}

The thermoelectric module is tightly clamped between the cooling jacket and the heater block. All the contact surfaces are filled with high thermal-conductivity grease in order to reduce the contact resistance. The operation of the test facility is fully automatic. The computer program will automatically decide the operating condition and run the test one by one until all the required tests are finished. The measured results are stored in a file with a standard format so that an analysis program can read for further analysis. 


\subsection{Determination of physical properties of a thermoelectric module}

The theoretical equations for the thermoelectric module performance include the voltage equation $[5,6]$ :

$V=\alpha\left(T_{\mathrm{H}}-T_{\mathrm{L}}\right)+I R$,

the input power equation:

$P=\alpha I\left(T_{\mathrm{H}}-T_{\mathrm{L}}\right)+I^{2} R$,

the cooling capacity equation:

$Q_{\mathrm{L}}=\alpha I T_{\mathrm{L}}-\frac{1}{2} I^{2} R-K_{\mathrm{t}}\left(T_{\mathrm{H}}-T_{\mathrm{L}}\right)$,

the total heat rejection equation:

$Q_{\mathrm{H}}=P+Q_{\mathrm{L}}=\alpha I T_{\mathrm{H}}-\frac{1}{2} I^{2} R-K_{\mathrm{t}}\left(T_{\mathrm{H}}-T_{\mathrm{L}}\right)$,

and COP is defined as

$C O P=\frac{Q_{\mathrm{L}}}{P}$,

where $\alpha$ is the Seebeck coefficient of the module, $V^{\circ} \mathrm{C}^{-1}$; $R$ is the total electrical resistance, ohm; $K_{\mathrm{t}}$ is the total thermal conductivity, $\mathrm{W}^{\circ} \mathrm{C}^{-1}$. An important physical property for the thermoelectric module is the figure of merit $Z$ which is defined as

$Z=\frac{\alpha^{2}}{K_{t} R}$

The measurement of the physical properties of a thermoelectric module $\left(\alpha, R\right.$ and $\left.K_{\mathrm{t}}\right)$ are quite simple. By using the present test facility, the Seebeck coefficient $\alpha$ can be measured from a pure conduction test, i.e. letting $I=0$. Measuring the hot-end and the cold-end temperatures, $T_{\mathrm{H}}$ and $T_{\mathrm{L}}$, and the induced thermoelectric voltage $V$, we can determine $\alpha$ from Eq. (1) with $I=0$.

Measuring $Q_{\mathrm{L}}$, at $I=0$, we can determine the thermal conductivity $K_{\mathrm{t}}$ from the heat conduction equation, i.e. Eq. (3) with $I=0$. Using the testing data of $V$ at various $I, T_{\mathrm{L}}, T_{\mathrm{H}}$, and the measured $\alpha$, we can determine the total resistance $R$ from Eq. (1). For easy implementation, a computer program was written to automatically read the test data and analyze the physical properties.

Fig. 2 presents the test results of a commercial thermoelectric module DT (with rated $Q_{\mathrm{Lmax}}=51.5 \mathrm{~W}$, $\Delta T_{\max }=64^{\circ} \mathrm{C}$ ). It shows that $\alpha, R$ and $K_{\mathrm{t}}$ are slightly functions of operating temperature. The figure of merit of the module DT is in the range of $1.56-1.67 \times 10^{-3} \mathrm{~K}^{-1}$ which is lower than the data given by the manufacturer.
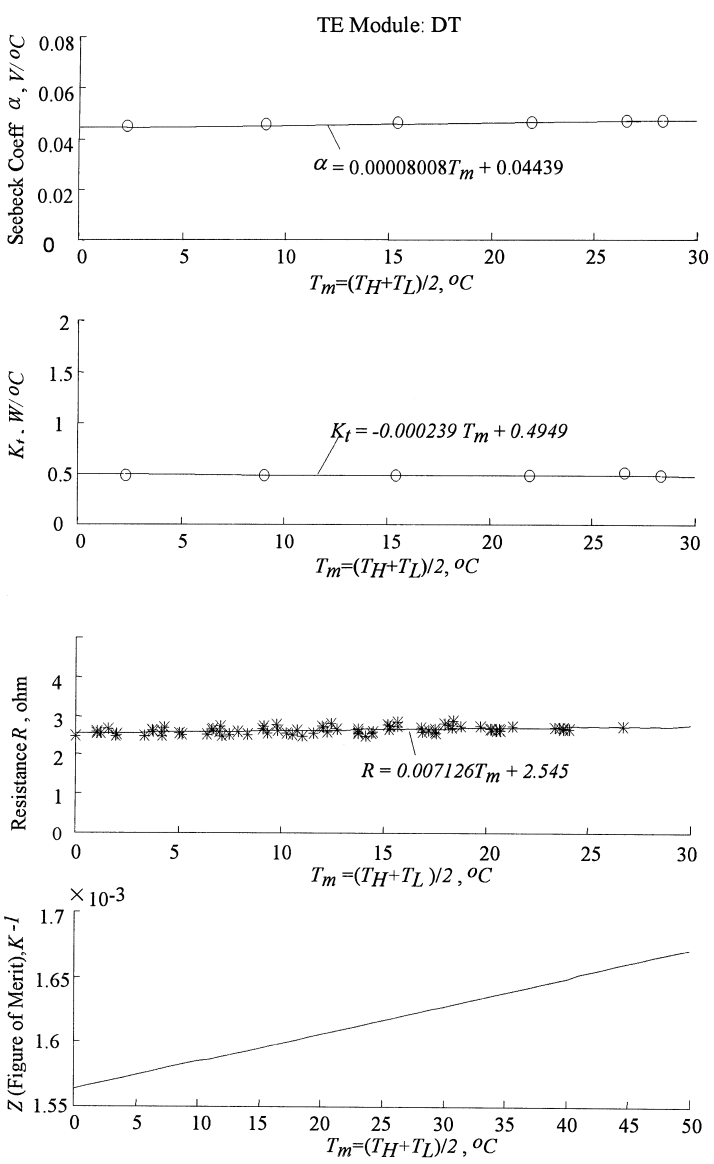

Fig. 2. Measured physical properties of the thermoelectric module DT.

Fig. 2. Propriétés physiques mesurées du module thermoélectrique DT.

\subsection{Measurement of performance curves of a thermoelectric module}

The aforementioned test facility is also used to measure the performance curves of a thermoelectric module at various $T_{\mathrm{H}}$ and $Q_{\mathrm{L}}$. Fig. 3 shows the performance curves of a thermoelectric module at $T_{\mathrm{H}}=27$ and $40^{\circ} \mathrm{C}$. We found that the measured $\Delta T$ at $T_{\mathrm{H}}=27^{\circ} \mathrm{C}$ and zero cooling capacity for various current $I$ coincide very well with the data given by the manufacturer. However, the deviation becomes large as the cooling capacity increases. This may result from the quality control in the manufacturing of the module. The measured results can be used to derive an empirical correlation. From Eq. (3), we have

$T_{\mathrm{H}}-T_{\mathrm{L}}=\frac{\alpha I T_{\mathrm{L}}-\frac{1}{2} I^{2} R-Q_{\mathrm{L}}}{K_{\mathrm{t}}}$ 
However, it is found that neither Eq. (7) nor (3) fits the test results. This is due to the fact that neither Eq. (7) nor (3) is theoretically derived from some simplifications and assumptions that may not hold. We found that the following relation is suitable for the thermoelectric module:

$$
T_{\mathrm{H}}-T_{\mathrm{L}}=\frac{A_{1} I+A_{2} I^{2}+A_{3} Q_{\mathrm{L}}}{A_{4} I+A_{5}}\left[1+A_{6}\left(T_{\mathrm{H}}-27\right)\right]
$$

where $T_{\mathrm{H}}$ and $T_{\mathrm{L}}$ are in ${ }^{\circ} \mathrm{C}$. Fig. 3 shows that Eq. (8) fits very well with the test results at $T_{\mathrm{H}}=27,35,40,45^{\circ} \mathrm{C}$ with the coefficients:

$A_{1}=2.483 ; \quad A_{2}=-0.2183 ; \quad A_{3}=-0.171 ;$

$A_{4}=0.005606 ; \quad A_{5}=0.09223 ; \quad A_{6}=0.011$.

Eqs. (1), (2) and (8) are the basic performance equations for the thermoelectric module. Using these equations and
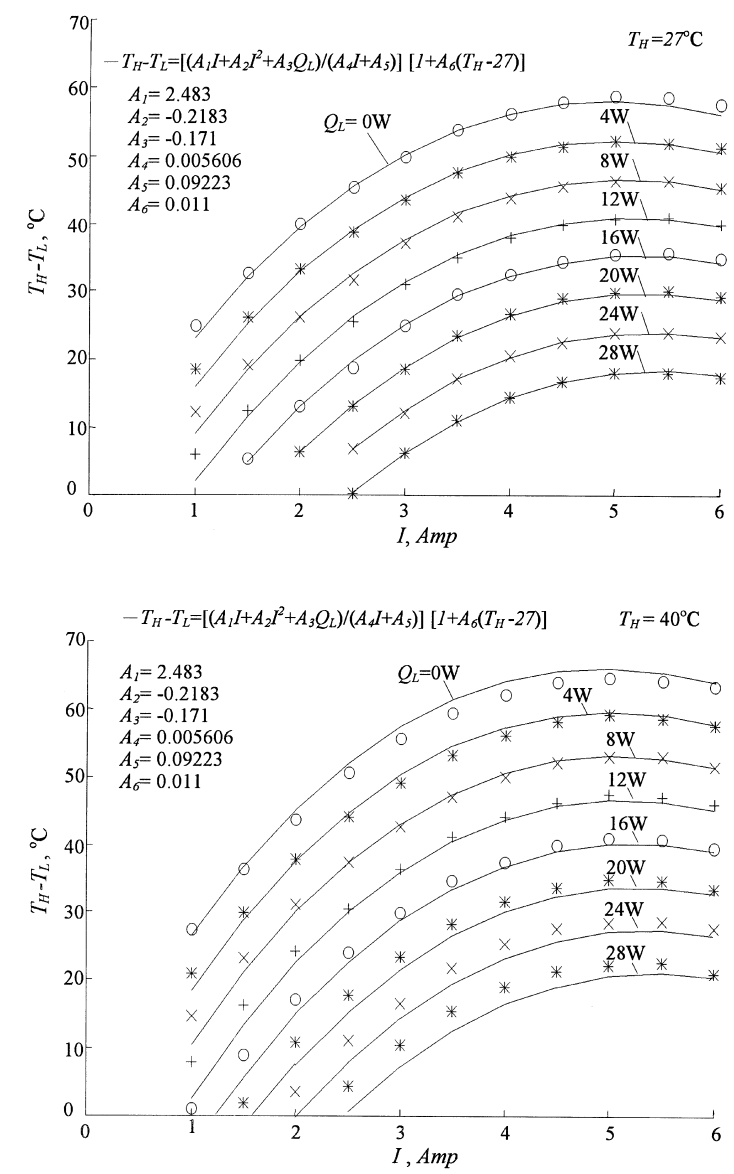

Fig. 3. Measured performance curves of the thermoelectric module DT.

Fig. 3. Courbe des performances du module thermoélectrique DT. the measured physical properties, $\alpha, R$ and $K_{\mathrm{t}}$, we can perform the system analysis of a thermoelectric cooler.

\section{System design analysis of a thermoelectric cooler}

\subsection{Performance simulation and system design implementation}

The thermal performance of a thermoelectric cooler depends on the thermoelectric module performance and the heat sink design. The heat released from a heat element is absorbed by the cold side of a thermoelectric
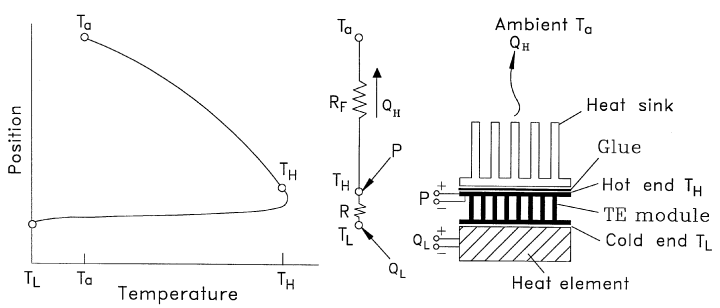

Fig. 4. Thermal network model of a thermoelectric cooler.

Fig. 4. Modèle du réseau thermique d'un refroidisseur thermoélectrique.

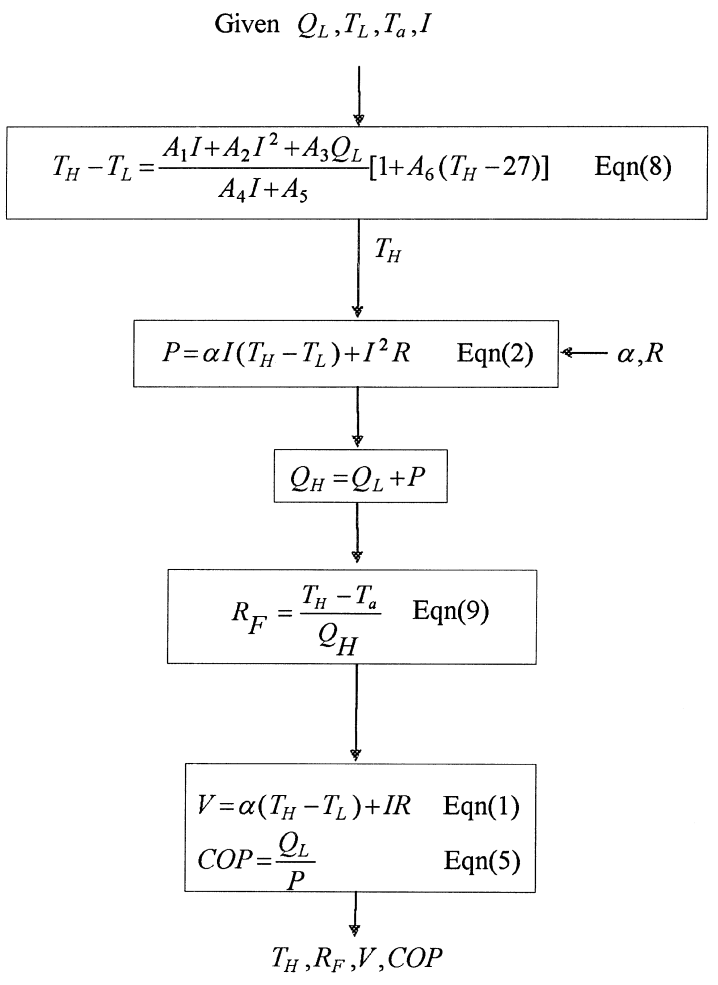

Fig. 5. System analysis flowchart for thermoelectric cooler.

Fig. 5. Schéma de l'analyse du système pour le refroidisseur thermoélectrique. 

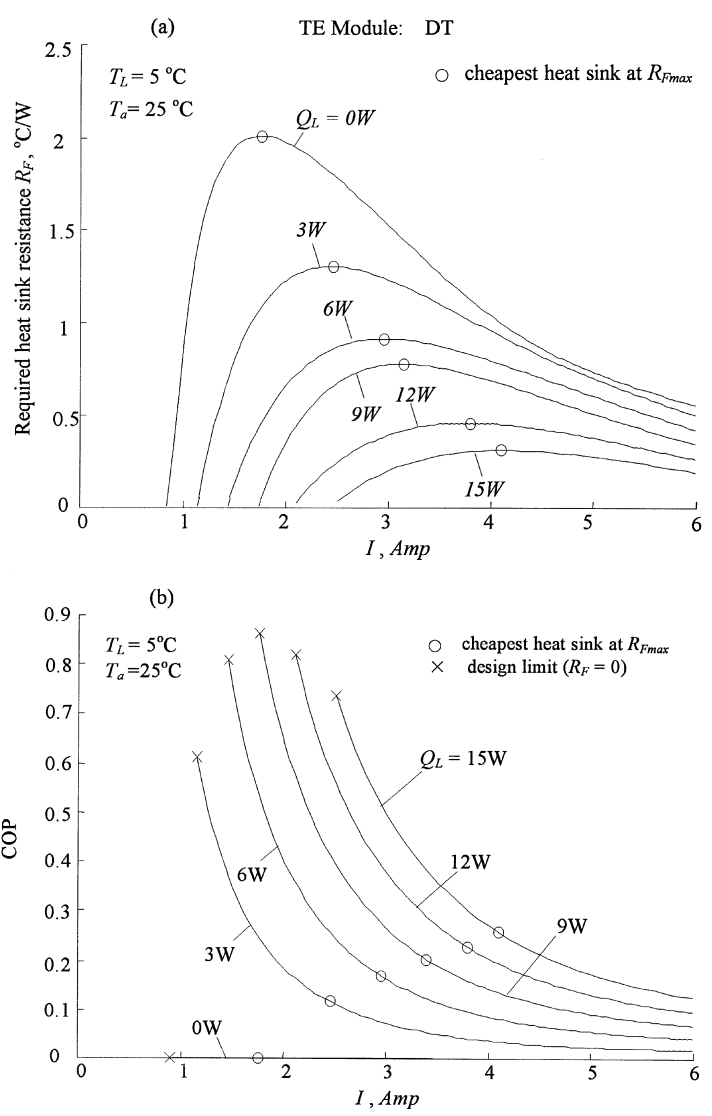

Fig. 6. System simulation results of thermoelectric cooler: (a) heat sink resistance; (b) COP.

Fig. 6. Résultats de la simulation du système du refroidisseur thermoélectrique. (a) Résistance du puits thermique ; (b) COP.

module and pumped to the hot side by the module. The pumped heat together with the input power to the module is then dumped to the ambient through a heat sink. Hence, we can draw a thermal network to represent the heat transfer process in a thermoelectric cooler as shown in Fig. 4, assuming no contact resistance.

The total heat transfer from the heat sink to the ambient $Q_{\mathrm{H}}$ depends on the thermal resistance of the heat sink $R_{\mathrm{F}}$ which is defined as

$Q_{\mathrm{H}}=\frac{T_{\mathrm{H}}-T_{\mathrm{a}}}{R_{\mathrm{F}}}$

The system analysis of a thermoelectric cooler can be carried out according to the flowchart shown in Fig. 5. Fig. 6(a) shows that the required heat sink thermal resistance $R_{\mathrm{F}}$ varies with the input current $I$ for a fixed cooling capacity $Q_{\mathrm{L}} . R_{\mathrm{F}}$ first increases with increasing $I$, reaches a maximum value, and then decreases with increasing $I$. The maximum value of $R_{\mathrm{F}}$ represents a poor

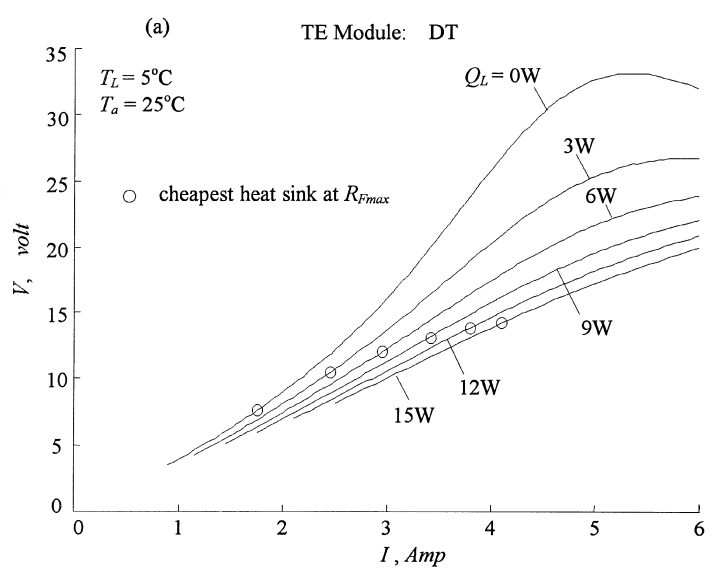

(b)

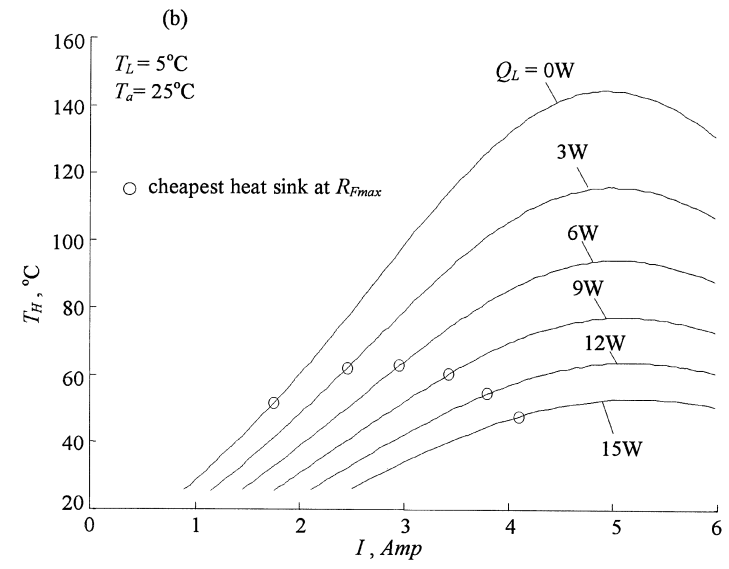

Fig. 7. System simulation results of thermoelectric cooler: (a) voltage; (b) hot-end temperature.

Fig. 7. Résultats de la simulation du système du refroidisseur thermoélectrique. (a) Voltage ; (b) Température côté chaud.

performance heat sink with larger thermal resistance, but corresponds to a cheapest heat sink.

For a fixed cooling capacity $Q_{\mathrm{L}}$, the COP of the thermoelectric cooler monotonically increases with decreasing $I$ as shown in Fig. 6(b). The extreme value of COP represents the design limit which corresponds to $R_{\mathrm{F}}=0$ (infinitely-large heat sink). These results reveal that the heat sink design is one of the key factors affecting the performance of a thermoelectric cooler. It is desirable to design a thermoelectric cooler with heat sink resistance as small as possible in order to increase the COP.

Fig. 7 shows the variations of applied voltage $V$ and hot-end temperature $T_{\mathrm{H}}$ of the thermoelectric module with current $I$ for various $Q_{\mathrm{L}}$.

Figs. 6 and 7 are the simulation results which can be used in the design of a thermoelectric cooler. In practice, many designers are restricted by his heat sink technology on hand. Therefore, the design of a thermoelectric cooler may start from the available heat sink technology with a known $R_{\mathrm{F}}$. For the desired $T_{\mathrm{L}}$ and $Q_{\mathrm{L}}$ with a 
given ambient condition $T_{\mathrm{a}}$, the performance curves of Fig. 6(a) can be used to determine the required current I. From Fig. 6(b), the COP can be predicted. Fig. 7 then gives the required voltage $V$ and the hot-end temperature $T_{\mathrm{H}}$ of the thermoelectric module.

\subsection{Verification of performance simulation}

To verify the above system design analysis, we designed and built a thermoelectric cooler and perform an experiment. The schematic diagram of the thermoelectric cooler is shown in Fig. 8. The thermoelectric module DT is used. The heat sink is made from extruded aluminum having a $6 \mathrm{~mm}$-thick $180 \times 150 \mathrm{~mm}$ base plate and $151.5 \mathrm{~mm}$-thick fins $(55 \mathrm{H} \times 150 \mathrm{~L})$ with $8 \mathrm{~mm}$ fin pitch. The thermal resistance of the heat sink from the base plate to the ambient is $0.2515^{\circ} \mathrm{C} / \mathrm{W}$ which is determined from a separate experiment with a cooling fan on the top of the fin. It is shown from Figs. 9 and 10 that, the agreement between the test and the calculating results is very good. This verifies the above system analysis.

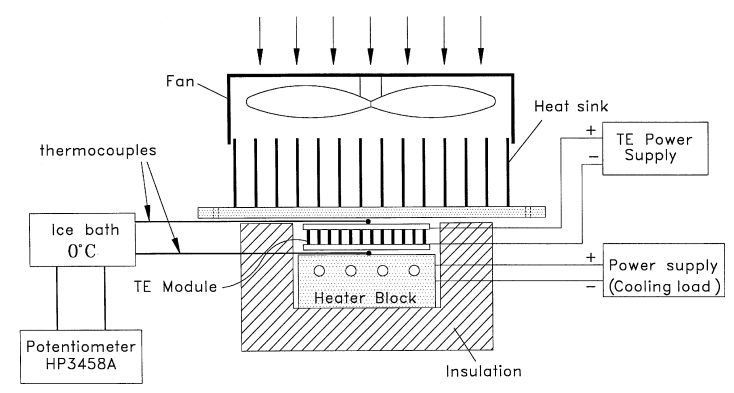

Fig. 8. Schematic diagram of a test thermoelectric cooler.

Fig. 8. Schéma du refroidisseur thermoélectrique utilisé.

\section{Optimum design of a thermoelectric cooler}

The empirical equation, Eq. (8), can be re-written as

$Q_{\mathrm{L}}=\frac{\left(A_{4} I+A_{5}\right)\left(T_{\mathrm{H}}-T_{\mathrm{L}}\right)}{A_{3}\left[1+A_{6}\left(T_{\mathrm{H}}-27\right)\right]}-\frac{A_{1} I+A_{2} I^{2}}{A_{3}}$.

From Eqs. (2) and (10) and the definition of COP, Eq. (5), we can carry out an optimal analysis. For fixed $T_{\mathrm{H}}$, $T_{\mathrm{L}}$, the optimum value of COP and $Q_{\mathrm{L}}$ exists as shown in Fig. 11. The thermoelectric cooler can be designed at maximum COP or at maximum cooling capacity. In many applications, the thermal efficiency is more important. Thus, the design based on the maximum COP is adopted in the present study. The corresponding optimal current, denoted as $I_{\text {opt }}$, can be found from Fig. 11.

For a fixed $T_{\mathrm{L}}$, an optimum current $I_{\text {opt }}$ can be found for a given $T_{\mathrm{H}}$. Repeating the calculation of Fig. 11 for different values of $T_{\mathrm{H}}$, we can determine the corresponding optimal currents $I_{\text {opt }}$ and plot Fig. 12. Furthermore, we can also find the cooling capacity, COP, heat sink resistance and voltage at each $I_{\mathrm{opt}}$. The variations of $Q_{\mathrm{opt}}, C O P_{\mathrm{opt}}$, $R_{\text {Fopt }}$ and $V_{\text {opt }}$ with $I_{\text {opt }}$ are shown in Figs. 13 and 14.

\subsection{System design based on the maximum cooling capacity attainable}

It is interesting to see that, in addition to the condition of optimal COP, there also exits a maximum value for the optimum cooling capacity, denoted as $Q_{\mathrm{opt}}$, as shown in Fig. 13(a). If both the optimum COP and the maximum cooling capacity are desired, we can start from Fig. 13(a) for the design of a thermoelectric cooler. By locating the maximum value of $Q_{\text {opt }}$ at Point A, we then determine a $I_{\mathrm{opt}}$. For the thermoelectric module
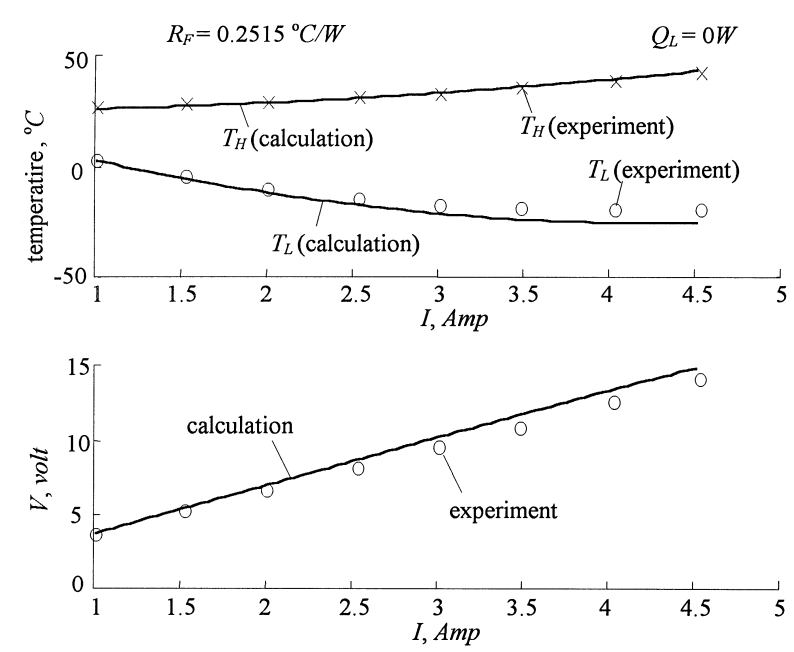

Fig. 9. Comparison of test data and simulation results at $Q_{\mathrm{L}}=0 \mathrm{~W}$.

Fig. 9. Comparaison des données d'essai et des résultats de la simulation pour $Q_{\mathrm{L}}=0 \mathrm{~W}$. 

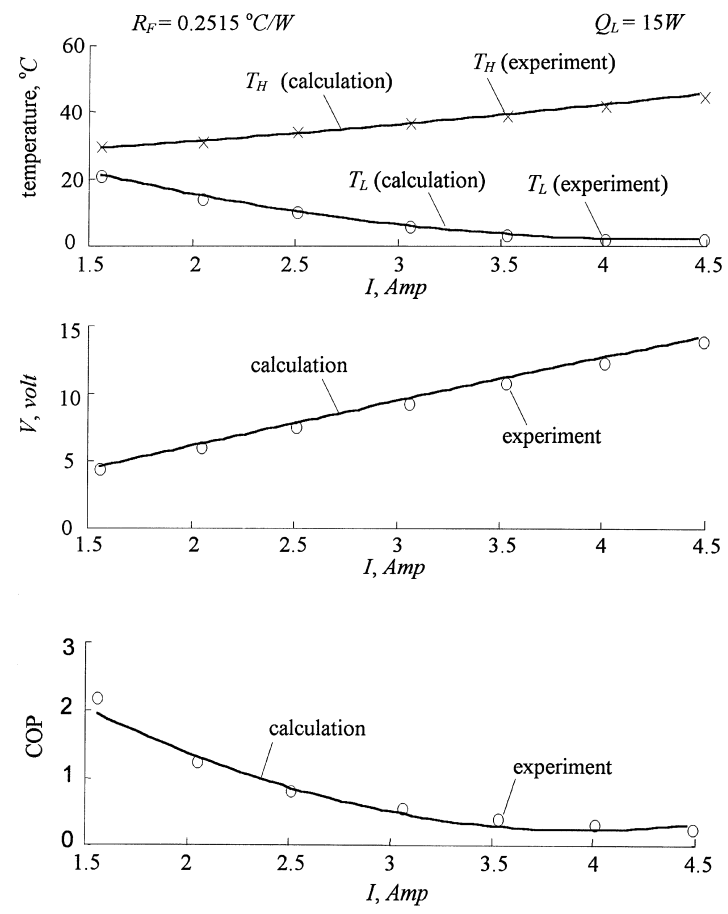

Fig. 10. Comparison of test data and simulation results at $Q_{\mathrm{L}}=15 \mathrm{~W}$.

Fig. 10. Comparaison des données d'essai et des résultats de la simulation pour $Q_{\mathrm{L}}=15 \mathrm{~W}$.

DT used in the present calculation, $I_{\mathrm{opt}}=2.5 \mathrm{~A}$ for the maximum value of $Q_{\text {opt }}$ at $9.87 \mathrm{~W}$. From Fig. 13(b), we determine $C O P_{\text {opt }}$ as 0.47 . From Fig. 14(a), we find that the required heat sink resistance $R_{\mathrm{Fopt}}$ at $I_{\mathrm{opt}}$ is $0.43^{\circ} \mathrm{C}$ $\mathrm{W}^{-1}$. The required voltage for the thermoelectric module $V_{\text {opt }}$ at $I_{\text {opt }}$ is $8.4 V$ from Fig. 14(b).

\subsection{System design based on the best heat sink technology available}

As mentioned previously, the best heat sink with a smallest $R_{\mathrm{F}}$ can provide a best performance of the thermoelectric cooler. Hence, the system design can also be made on the basis of the heat sink technology available. In this case, the design will start from Fig. 14(a). For example, if the heat sink available has a $R_{\mathrm{F}}$ value at $0.2515^{\circ} \mathrm{C} \mathrm{W}^{-1}$ as the one used in the present experiment, then we can determine the optimal current $I_{\text {opt }}$ to be 2.1A (Point B). From Fig. 13(a), we find that the optimal cooling capacity $Q_{\text {opt }}$ is $9.61 \mathrm{~W}$ which is slightly less than the maximum value $9.87 \mathrm{~W}$ at Point A. From Fig. 13(b), $C O P_{\text {opt }}$ is around 0.67 which is much larger than the $C O P_{\text {opt }}$ at $Q_{\text {opt }}$ (Point A). From Fig. 14(b), the voltage to the thermoelectric module at $I_{\mathrm{opt}}=2.1 \mathrm{~A}$ is $6.9 \mathrm{~V}$. The above two design examples are used to illustrate how to implement the system simulation results in the design of a
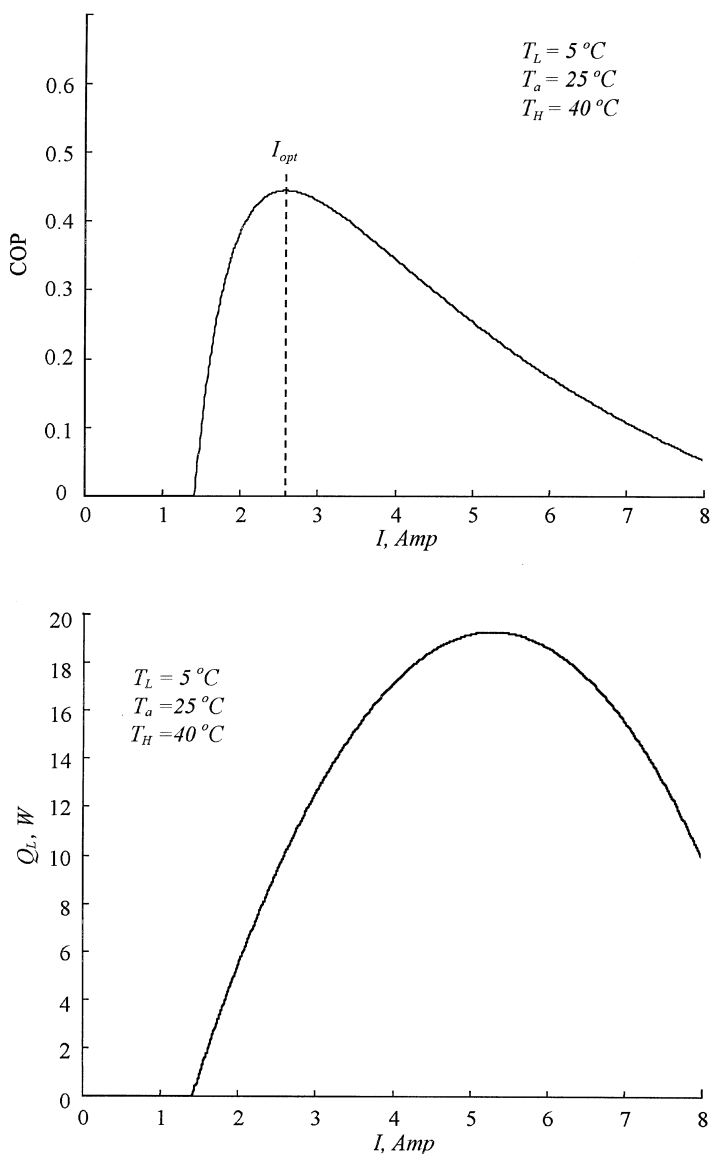

Fig. 11. Optimal COP and optimal cooling capacity at fixed $T_{\mathrm{L}}, T_{\mathrm{H}}$ and $T_{\mathrm{a}}$.

Fig. 11. COP et puissance frigorifique optimaux à $T_{\mathrm{L}}, T_{\mathrm{H}}$ et $T_{\mathrm{a}}$.

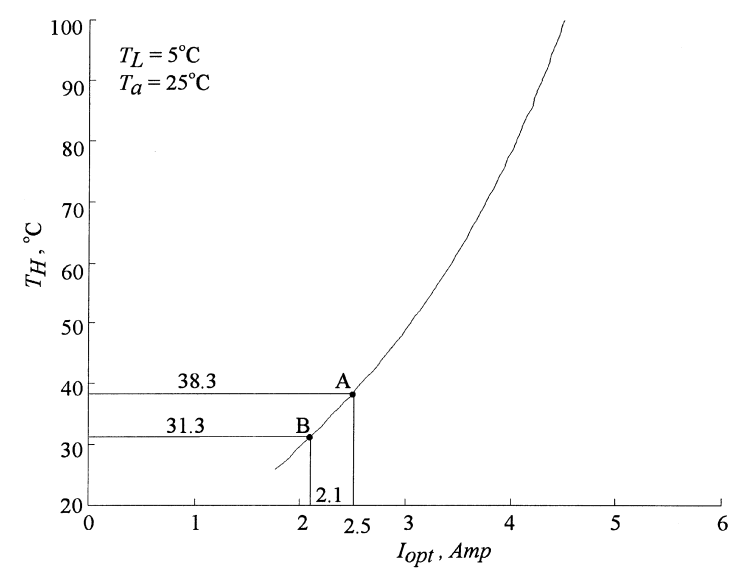

Fig. 12. Simulation results at the condition of optimal COP: variation of hot-end temperature at the condition of optimal COP.

Fig. 12. Résultats de la simulation au COP optimal : variations de la température côté chaud dans les conditions de COP optimal. 


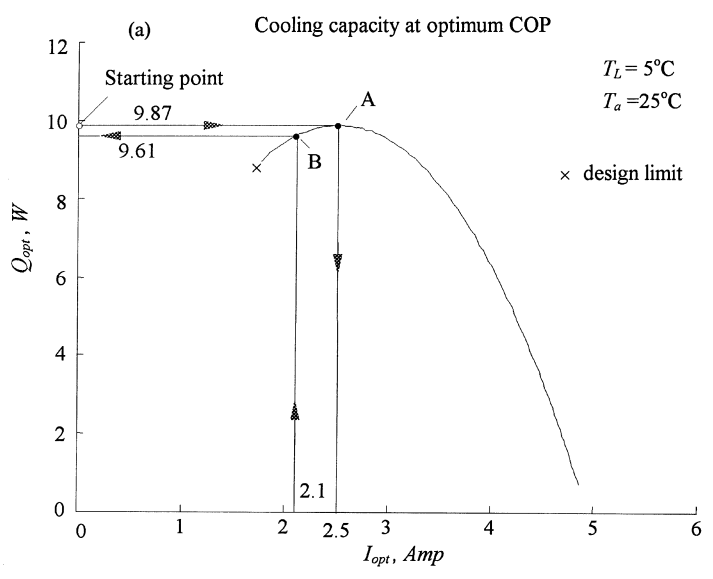

(b)

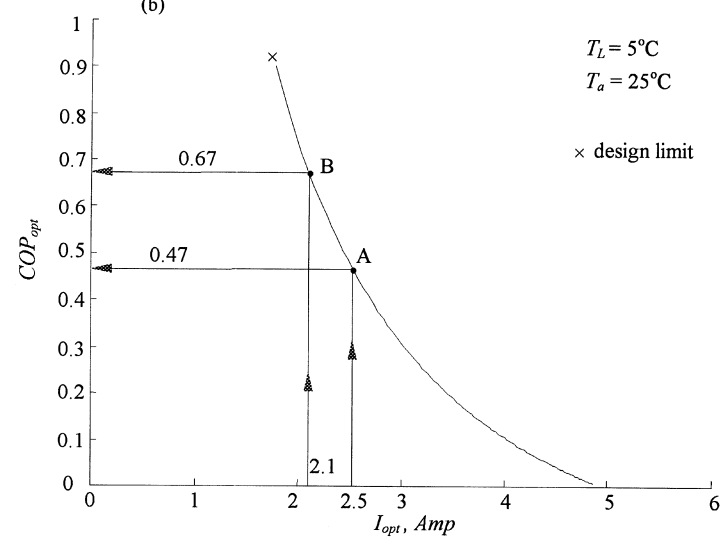

Fig. 13. Simulation results at the condition of optimal COP: (a) optimal cooling capacity; (b) optimal COP.

Fig. 13. Résultats de la simulation au COP optimal: (a) puissance frigorifique optimale ; (b) COP optimal.

thermoelectric cooler. For different thermoelectric modules, the design procedure including the performance test of the module is the same.

\section{Discussions and conclusion}

The present study develops a design method of thermoelectric cooler. It is suggested that the thermoelectric module be tested to determine its physical properties and the performance curves, especially when the manufacturer is not able to provide the basic data of a thermoelectric module. An automatic test apparatus was thus developed in the present study to illustrate the testing method. The test facility can be simplified if time or budget is limited. Basically, the results from a simple thermal conduction test with $I=0$ can be used to determine $\alpha, R$, and $K_{\mathrm{t}}$. The performance curves ( $\Delta T$ vs $I)$ at various $Q_{\mathrm{L}}$ and $T_{\mathrm{H}}$ can also be measured by using a simple apparatus. The cooling jacket used in the present
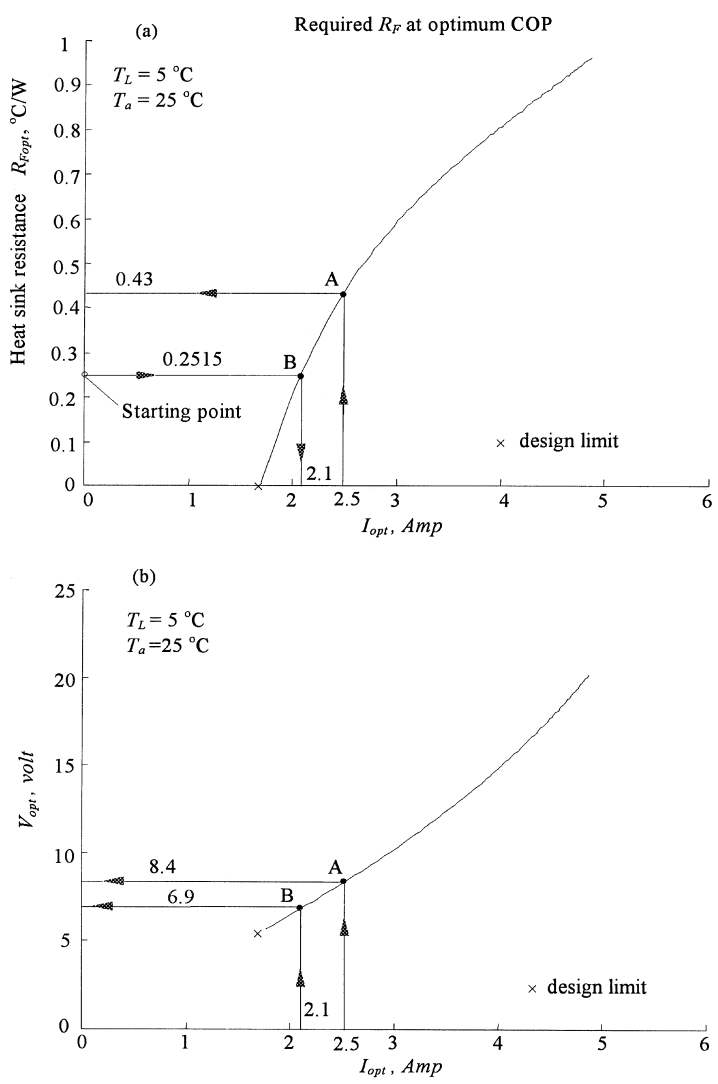

Fig. 14. Simulation results at the condition of optimal COP: (a) heat sink resistance; (b) voltage.

Fig. 14. Résultats de la simulation au COP optimal: (a) résistance du puits thermique ; (b) voltage.

study can be replaced by a high-performance heat sink with a DC cooling fan. $T_{\mathrm{H}}$ can thus be controlled to a constant value by regulating the fan speed. The cooling jacket can also be replaced by a similar water cooling jacket used in the present study but with a DC pump for water circulation. $T_{\mathrm{H}}$ can thus be controlled to a constant value by regulating the water flowrate through the DC voltage input to the pump.

The vacuum jacket used in the present study may not be necessary either. A good insulation of the heat element block used for the cooling capacity emulation is sufficient to replace the vacuum jacket. Manual operation for the test is also feasible if automation is difficult.

The test results are used to fit the empirical relation, Eq. (8), by using regression analysis. A nonlinear programming method can be chosen for the analysis. It is very easy to find a computer package from a software library. For some modules, Eq. (8) may not be able to fit the test results. In this case, a modification of the equation can be made as long as an appropriate empirical relation 

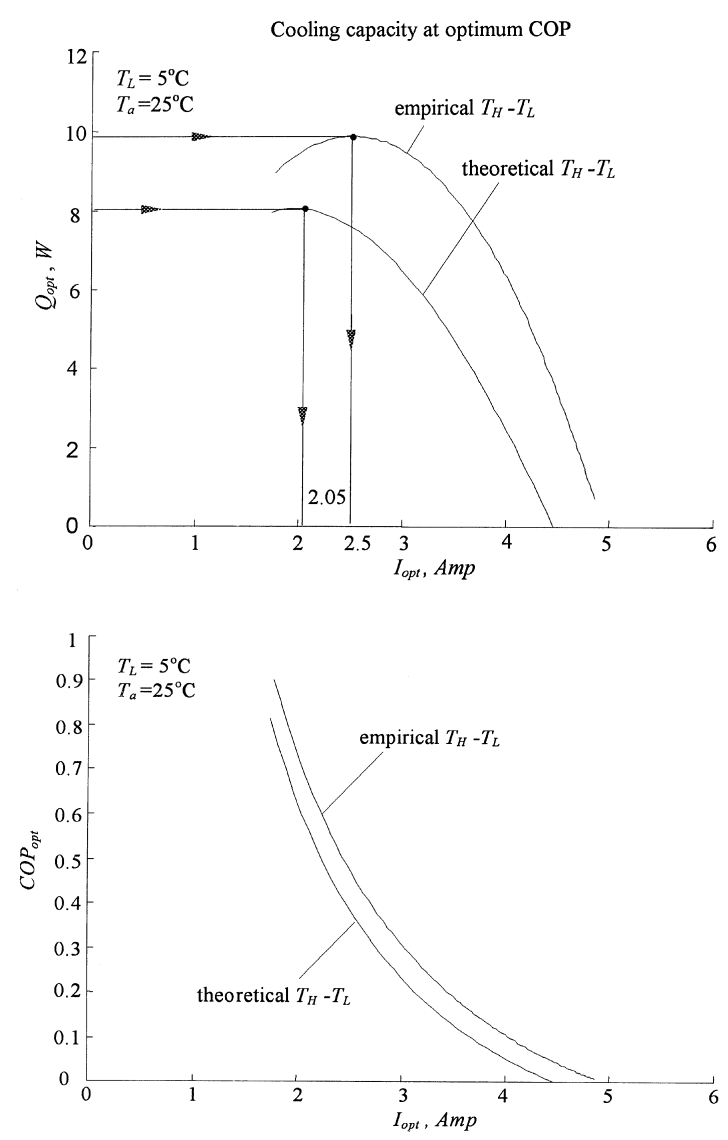

Fig. 15. Comparison of simulation at the condition of optimal COP using theoretical and empirical relations of the thermoelectric module.

Fig. 15. Comparaison de la simulation au COP optimal à l'aide des relations théoriques et empiriques du module thermoélectrique.

can be found to fit the test data. It is best for a designer of thermoelectric cooler if the module supplier can provide all the aforementioned data of the thermoelectric module. The manufacturer can perform a standard test for the module using a more sophisticated apparatus to determine the physical properties and the performance curves including the empirical equation. If this can be done, the designer can concentrate on the system design only. We develop a system simulation scheme for the system design of a thermoelectric cooler using a thermal network model and the test results of the module. The thermal resistance of heat sink is used as one of the key parameters in the design of a thermoelectric cooler. The system simulation results show that there exists a cheapest heat sink with the highest thermal resistance for the design of a thermoelectric cooler. The system simulation is shown to coincide with the experimental data of a cooler using a heat sink with thermal resis-
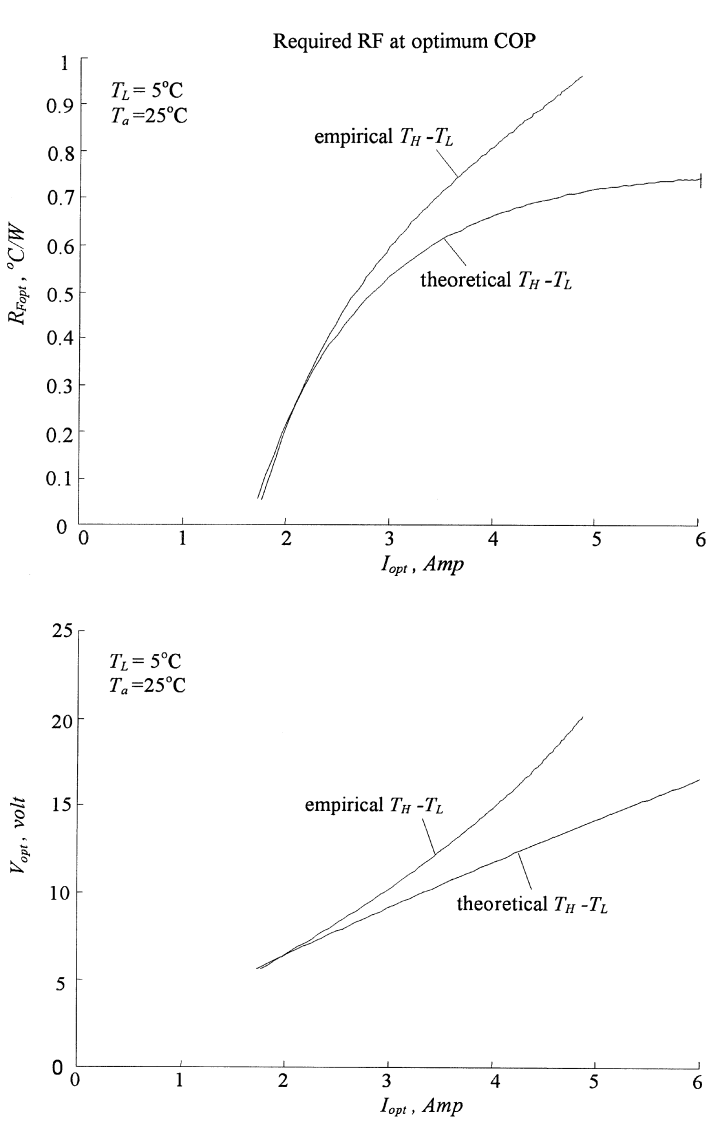

Fig. 16. Comparison of simulation at the condition of optimal COP using theoretical and empirical relations of the thermoelectric module.

Fig. 16. Comparaison de la simulation au COP optimal à l'aide des relations théoriques et empiriques du module thermoélectrique.

tance $0.2515^{\circ} \mathrm{C} \mathrm{W}^{-1}$. The system simulation can provide various plots for system design application.

An optimal design at the conditions of optimal COP is also studied. It is found that the optimal design can be made either on the basis of the maximum value of cooling capacity at the conditions of optimal COP, or on the basis of the best heat sink technology available. For the thermoelectric module used in the present study, the required heat sink resistance at cold-end temperature $5^{\circ} \mathrm{C}$ changes from $0.43^{\circ} \mathrm{C} \mathrm{W}^{-1}$ for the condition of the cheapest heat sink to $0.2515^{\circ} \mathrm{C} \mathrm{W}^{-1}$ for the condition of the best available heat sink, about $42 \%$ increase in heat sink performance. However, the optimal COP increases from 0.47 for the cheapest heat sink to 0.67 for the best available heat sink, about $43 \%$ increase in COP. There is only a $2.7 \%$ drop in the cooling capacity for the best available heat sink design. The extreme COP (with $R_{\mathrm{F}}=0$ ) is around 0.9 as shown in Fig. 13(b). 
Using the simulated graphs, we can easily perform an optimal design of a thermoelectric cooler. In case that only the physical properties of the thermoelectric module $\alpha, R$, and $K_{\mathrm{t}}$ are known either from the manufacturer or from a simple testing, we may use them in conjunction with Eq. (7) to derive the optimal operation equations $[5,6]$ and perform the system simulation. This may however cause some error in the design as shown in Figs. 15 and 16. Nevertheless, this can provide a preliminary design from which a final design will be obtained by the method of trials and errors in hardware development. The system design of the thermoelectric cooler based on the simulation results shown in Figs. 6 and 7 provides no optimal design. Hence, it is not recommended for use. However, Figs. 6 and 7 can be used in the design when the cheapest heat sink is the major concern. It should be pointed out that the present design method of a thermoelectric cooler is different from that developed by Marlow Industries [4,6]. Marlow's method uses the maximum design parameters and a universal performance chart for modules made by Marlow Industries Inc. only. Most manufacturers did not supply this kind of chart. On the other hand, the universal performance chart can be accurately derived only if the quality control of the module manufacturing process is excellent. This is however questionable. In general, Marlow's method is more suitable for the selection of thermoelectric module since it does not take into account the effect of the thermal resistance of heat sink. The present study uses the thermal resistance of the heat sink as one of the key parameters in the design of a thermoelectric cooler. This eliminates the need to carry out the complicated heat transfer analysis of a heat sink during the system analysis [7] and thus simplifies the system design procedure. The heat sink can be designed without too much difficulty once the required heat sink thermal resistance $R_{\mathrm{F}}$ has been determined from the system simulation charts.

\section{Acknowledgements}

The present study was supported by the National Science Council, ROC, Taiwan, through Grant No. NSC81-0401-E002-505.

\section{References}

[1] Andersen JR. Thermoelectric air conditioner for submarines. Adv Energy Conv 1962;2:241-8.

[2] Marlow R, Buist RJ, Nelson JL. System aspects of thermoelectric coolers for hand held thermal viewers. Fourth international conference on thermoelectric energy conversion (IEEE Calalog No. 82CH1763-2), 1982. p. 125-9.

[3] Mei VC, Chen FC, Mathiprakasam B. Comparison of thermoelectric and vapor cycle technologies for groundwater heat pump application. ASME J Solar Energy Eng 1989;111:353-7.

[4] Anon. Thermoelectric cooler selection guide. Marlow Industries, Inc., 1990.

[5] Soo SL. Direct energy conversion. Englewood Cliffs (NJ): Prentice Hall, Inc, 1968. (chapter 5)

[6] Goldsmid HJ. Electronic Refrigeration. Englewood Cliffs(NJ): Prentice-Hall, Inc., 1986.

[7] Chen K, Bwilliam SB. An analysis of the heat transfer rate and efficiency of thermoelectric cooling systems. Int $\mathbf{J}$ Energy Res 1996;20:399-417. 